\title{
The optimal screening interval for gastric cancer using esophago-gastro-duodenoscopy in Japan
}

\author{
Daiki Kobayashi", Osamu Takahashi, Hiroko Arioka and Tsuguya Fukui
}

\begin{abstract}
Background: Gastric cancer is one of the most significant diseases, and esophago-gastro-duodenoscopy (EGD) is one of screening methods for gastric cancer. This study was conducted to identify the optimal screening interval for gastric cancer using EGD in healthy adults.

Methods: A retrospective cohort study was conducted on 3,723 healthy participants without a known diagnosis of gastric cancer at baseline from January 2005 to December 2010. Participants underwent annual health screenings, including EGD, at the Center for Preventive Medicine at St Luke's International Hospital, a community teaching hospital in Japan. Participants with cytological abnormalities underwent further examination. A generalized estimating equation (GEE) was used to analyze the longitudinal data. We decided $0.5 \%$ of incidence of gastric cancer as a cutoff point for interval.
\end{abstract}

Results: The mean age (SD) of the participants was 55 (11) years, and 1,879 (50.5\%) were male. During the study period, gastric cancer was detected in 35 participants. However, the incidence varied based on their ages. In the age groups $<40,40-49,50-59,60-69$ and $\geq 70$ years old, the 5-year cumulative incidences ( $95 \% \mathrm{Cl}$ ) of gastric cancer were $0 \%(0-0 \%), 0.3 \%(0.1-1.0 \%), 1.0 \%(0.5-1.8 \%), 1.4 \%(0.8-2.4 \%)$ and $1.9 \%(0.8-3.8 \%)$, respectively. The odds ratios of the incidence of gastric cancer per year, which were evaluated using GEE models for the age groups 40-49, 50-59, 60-69 and $\geq 70$ years old, were 1.51 (95\%Cl: 0.91-2.49), 1.94 (95\%Cl: 1.31-2.86), 1.59 (95\%Cl: 1.23-2.06) and 1.46 (95\% Cl: 1.06-2.02), respectively.

Conclusions: A screening for gastric cancer using EGD may be appropriate annually for healthy people over 70 years old, every two or three years for people 60-69 years old and every four years for people 50-59 years old. People younger than 50 years old may only need repeat screenings every five years or more.

\section{Background}

Approximately 776,000 patients die from gastric cancer worldwide each year [1]. Japan has one of the highest rates of gastric cancer in the world; approximately 50,000 patients in Japan die from gastric cancer each year [2].

Some countries with high incidences of gastric cancer, including Japan [3], Chile [4] and Venezuela [5], recommend mass screening for gastric cancer, while other countries do not recommend routine screening [6]. In these high risk countries, mass screening for gastric cancer is expected to increase the early detection rate and reduce the mortality from gastric cancer based on previous large-scale case control studies and reviews $[7,8]$.

\footnotetext{
* Correspondence: daikoba@luke.or.jp

Division of General Internal Medicine, Department of Internal Medicine, St. Luke's International Hospital, Tokyo, Japan
}

Screening strategies for gastric cancer, however, are different among these high incidence countries. Esophago-gastro-duodenoscopy (EGD) is a screening method that is readily available and recommended by some experts in Japan [9]. Although there is a systematic review which recommends barium $x$-ray [10], the sensitivity of barium $\mathrm{x}$-rays is lower than that of EGD. Considering the fact that approximately $40 \%$ of gastric cancers are still undetected [11], higher sensitivity of screening method is of paramount importance. Moreover, the incidence of complications during EGDs was reported as low as $0.012 \%$ and the mortality rate was only $0.001 \%$ in Japan [12]. Finally, EGD was shown to be cost effective in a systematic review [13].

However, the optimal interval of EGD screening for gastric cancer is yet to be determined. Therefore, we

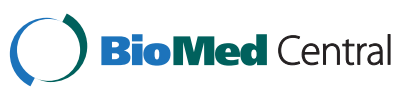


evaluated the optimal interval for EGD as a gastric cancer screening using a 5 -year cohort.

\section{Methods}

\section{Study participants}

From January 2005 to December 2010, all participants ( $\geq 20$ years old) who underwent EGD as a part of an annual health check-up program at the Center for Preventive Medicine at St. Luke's International Hospital in Tokyo, Japan, were enrolled in this cohort study. We included all participants who have completed 5 years follow up. We also included patients who were found gastric cancer during study period, even if they have not completed the remaining years. We excluded people with a diagnosis of gastric cancer at baseline. Previous EGD was not restricted in our study.

\section{Data collection}

We extracted data from the electronic health records of participants who had annual health screenings in 2005 (baseline year), 2006 (year 1), 2007 (year 2), 2008 (year 3), 2009 (year 4) and 2010 (year 5). The participants diagnosed with gastric cancer based on cytology were further evaluated at the Department of Gastroenterological Medicine or Digestive Surgery at St. Luke's International Hospital. The cytology was evaluated by two pathologists independently. We aggregated information from the participants who were determined to have gastric cancer by cytology and were evaluated at the other hospitals. The St. Luke's International Hospital's ethics committee approved the protocol for this study.

\section{Measurements}

The annual health check-up program contained an initial evaluation during which demographic and medical history information was collected. An EGD was performed by a gastroenterological specialist, and the cytological specimens were evaluated by two independent pathologists. Participants were divided into four age brackets: under 40 years of age, $40-49$ years, 50-59 years, 60-69 years and 70 years or older. The incidence of gastric cancer, the odds ratio of the incidence over five years and the proportion of gastric cancers to the number of biopsies were used as indicators to define the optimal intervals for screening. An incidence of $0.5 \%$ for gastric cancer was considered the cutoff point based on a previous interval study and the Japanese prevalence of gastric cancer [14].

\section{Statistical methods}

Data were analyzed using descriptive statistics, including the mean, variance, standard deviation (SD), and percentage. Chi-squared and Fisher's exact tests were used for cross-tabulated data, and t-tests for continuous data.

Table 1 Participant characteristics

\begin{tabular}{|c|c|c|c|c|}
\hline & $\begin{array}{l}\text { Gastric cancer patients } \\
\text { over five years }(n=35)\end{array}$ & $\begin{array}{l}\text { Normal participants } \\
\quad(n=3,688)\end{array}$ & $\begin{array}{c}\text { Total } \\
(n=3,723)\end{array}$ & $\begin{array}{c}\text { Mean difference } \\
\text { (p-value) }\end{array}$ \\
\hline Age, mean (SD) years & $62(9)$ & $55(12)$ & $55(12)$ & $<0.01$ \\
\hline Gender, male (\%) n & $25(71.4)$ & $1,854(50.3)$ & $1,879(50.5)$ & $<0.01$ \\
\hline BMI, mean (SD) kg/m [2] & $23.8(3.1)$ & $22.5(3.1)$ & $22.5(3.1)$ & 0.01 \\
\hline SBP mean (SD), mmHg & $125.4(13.6)$ & $120.7(18.2)$ & $120.8(18.2)$ & 0.05 \\
\hline DBP mean (SD), mmHg & $77.1(7.9)$ & $74.9(11.3)$ & $75.0(11.3)$ & 0.12 \\
\hline Heart rate mean $(S D), b p m$ & $69.5(9.4)$ & $73.4(11.3)$ & $73.3(11.3)$ & 0.04 \\
\hline White blood cell mean (SD), ${ }^{*} 10[3] / \mu \mathrm{l}$ & $5.6(1.5)$ & $5.1(1.4)$ & $5.1(1.4)$ & 0.06 \\
\hline Hemoglobin mean (SD), g/dl & $14.1(1.0)$ & $13.9(1.3)$ & $13.9(1.3)$ & 0.21 \\
\hline Platelet mean (SD), ${ }^{*} 10[6] / \mu \mathrm{l}$ & $224.2(43.5)$ & $234.4(51.0)$ & $234.3(51.0)$ & 0.24 \\
\hline Fasting blood sugar mean (SD), $\mathrm{mg} / \mathrm{dl}$ & $108.3(18.8)$ & $101.5(17.2)$ & $101.6(17.3)$ & 0.39 \\
\hline HgbA1c mean (SD), \% & $5.3(0.7)$ & $5.2(0.6)$ & $5.2(0.6)$ & 0.27 \\
\hline LDL-cho mean (SD), mg/dl & $117.0(21.8)$ & $120.5(29.0)$ & $120.5(29.0)$ & 0.47 \\
\hline HDL-cho mean (SD), mg/dl & $58.2(12.8)$ & $62.8(15.7)$ & $62.7(15.7)$ & 0.08 \\
\hline TG mean (SD), mg/dl & $107.4(53.0)$ & $102.8(70.7)$ & $102.8(70.5)$ & 0.70 \\
\hline Family history of gastric cancer $n(\%)$ & $8(1.2)$ & $677(18.4)$ & $685(18.4)$ & 0.31 \\
\hline Alcohol habit n (\%) & $24(68.6)$ & $2,157(58.5)$ & $2,181(58.6)$ & 0.15 \\
\hline Smoker: Brinckman index n (SD) & $430.7(648.0)$ & $210.6(412.7)$ & $21.7(415.9)$ & 0.05 \\
\hline Salt intake: g per day g (SD) & $12.7(3.4)$ & $12.2(3.8)$ & $12.2(3.8)$ & 0.44 \\
\hline Gastric ulcer n (\%) & $3(1.2)$ & $239(6.5)$ & $242(6.5)$ & 0.40 \\
\hline
\end{tabular}

Number of cigarettes smoked per day times the number of smoking years. 


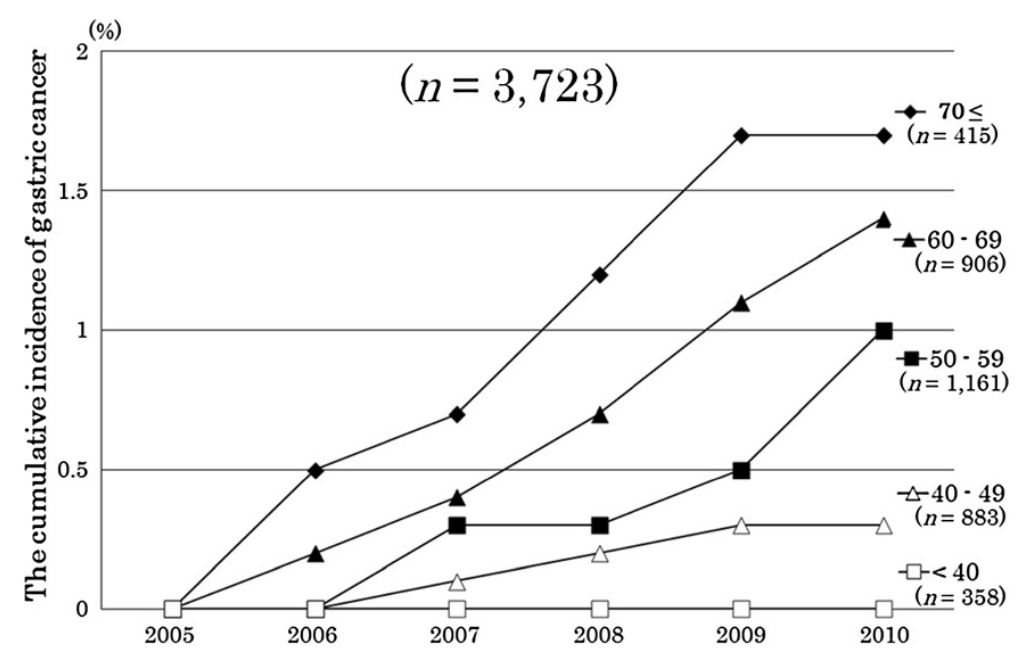

Figure 1 The cumulative incidence of gastric cancer for 5 years by age group.

Additionally, generalized estimating equations (GEE) [15], which were adjusted for possible risk factors, such as age, gender, alcohol consumption, smoking, family history, past medical history of gastric ulcers, salt intake and body mass index (BMI) [16-19], were used to evaluate the odds ratio of the cumulative incidence of gastric cancer [20]. GEE is performed to estimate the parameters of a generalized linear model with a possible unknown correlation between outcomes [21]. With this analysis, we can estimate likelihood with considering correlation matrix for the vector of repeated observations from each subject [22].

The majority of the data analyses were performed using the SPSS software 15.0J (SPSS Japan, Tokyo, Japan), except for the 95\% confidence intervals (CI) based on an exact binominal [23] and the GEE methods which were calculated using the Stata version 10 (STATA Corp., College Station, TX, USA).

\section{Results}

From January 2005 to December 2010, 3,723 participants completed all five yearly health screenings. The mean age (SD) of participants was 55 (12) years, and 1,879 participants (50.5\%) were male. The mean (SD) body mass index (BMI) was $22.5(3.1) \mathrm{kg} / \mathrm{m}$ [2]. Of the participants, 685

Table 2 Types of gastric cancer

\begin{tabular}{|c|c|c|c|c|c|c|}
\hline & $<40$ & $40-49$ & $50-59$ & $60-69$ & $\geq 70$ & Total \\
\hline Adenocarcinoma & 0 & 0 & 7 & 11 & 6 & 24 \\
\hline MALT ${ }^{*}$ Iymphoma & 0 & 0 & 3 & 2 & 1 & 6 \\
\hline Signet cell carcinoma & 0 & 3 & 1 & 0 & 0 & 4 \\
\hline Carcinoid & 0 & 0 & 1 & 0 & 0 & 1 \\
\hline Total & 0 & 3 & 12 & 13 & 7 & 35 \\
\hline
\end{tabular}

MALT*: Mucosa-associated lymphoid tissue.
(18.4) had a family history of gastric cancer, and 242 (6.5) had a past medical history of gastric cancer. Other baseline characteristics are shown in Table 1.

After 5 years, the cumulative incidence of gastric cancer was $0.9 \%$ (95\% CI, 0.7-1.3). However, the incidence varied greatly between age groups. At 5 years, the participants who were $<40,40-49,50-59,60-69$ and $\geq 70$ years old at baseline had cumulative incidences $(95 \% \mathrm{CI})$ of gastric cancer of $0 \%(0-0 \%), 0.3 \%(0.1-1.0 \%), 1.0 \%$ $(0.5-1.8 \%), 1.4 \%(0.8-2.4 \%)$ and $1.9 \%(0.8-3.8 \%)$, respectively (Figure 1).

During this 5 years period, 964 biopsies were performed, and 35 patients (3.6\%, 95\%CI: 2.5\%-5.0\%) were diagnosed with gastric cancer. All of them were followed throughout the study period (100\%). Of these patients, 24 had adenocarcinoma, 6 had mucosa-associated lymphoid tissue (MALT) lymphoma, 4 had signet cell carcinoma, and 1 had carcinoid (Table 2). Among 24 patients with adenocarcinoma, 20 were able to be followed up with their stage of cancer. 17 patients were Stage IA, and 3 patients were Stage IB.

The patients with MALT lymphoma were treated by eradicating of $H$. pylori. Among other patients, 20 were determined to have cancer at an early stage and were treated with endoscopic submucosal dissection (ESD), and 9 underwent gastrectomy (Table 3).

Table 4 shows the ratio of the incidence of gastric cancer per the number of biopsies. At 5 years, the participants who were $<40,40-49,50-59,60-69$ and $\geq 70$ years old at baseline had ratios $(95 \% \mathrm{CI})$ of $0 \%(0-0 \%)$, $1.9 \%(0.4-5.4 \%), 3.5 \%(1.8-6.0 \%), 4.5 \%(2.4-7.6 \%)$ and $4.8 \%(2.0-9.7 \%)$, respectively. The ratio $(95 \% \mathrm{CI})$ for all participants was 3.6 (2.5-5.0\%).

The odds ratios for the incidence of gastric cancer per year were estimated using GEE models adjusted for possible 
Table 3 Types of treatment for gastric cancer

\begin{tabular}{lrrrrrr}
\hline & $<\mathbf{4 0}$ & $\mathbf{4 0 - 4 9}$ & $\mathbf{5 0 - 5 9}$ & $\mathbf{6 0 - 6 9}$ & $\mathbf{2 7 0}$ & Total \\
\hline ESD $^{*}$ & 0 & 1 & 4 & 11 & 4 & 20 \\
Gastrectomy & 0 & 2 & 5 & 0 & 2 & 9 \\
H. pylori eradication & 0 & 0 & 3 & 2 & 1 & 6 \\
\hline Total & 0 & 3 & 12 & 13 & 7 & 35 \\
\hline
\end{tabular}

ESD*: Endoscopic submucosal dissection.

risk factors, including age, gender, alcohol consumption, smoking, family history, past medical history of gastric ulcers, salt intake and BMI. The independent odds ratios for the incidence of gastric cancer in the 40-49, 50-59, 6069 and $\geq 70$ years old age groups were 1.51 (95\%CI: 0.91 2.49), 1.94 (95\%CI: 1.31-2.86), 1.59 (95\%CI: 1.23-2.06) and 1.46 (95\%CI: $1.06-2.02$ ), respectively. None of the participants who were $<40$ years old had gastric cancer. (Table 5 ) Although there was no statistical relationship between gastric cancer and other variables, high BMI tended to be associated with high incidence of gastric cancer.

\section{Discussion}

This study showed that the incidence rates of gastric cancer significantly differed according to age. Accordingly, our recommended screening intervals were based on age brackets. For patients over 70 years old, screening for gastric cancer every year may be appropriate, and for patients 60-69 years old, every two or three years, for patients 50-59 years old, every three or four years, and for patients 40-49 years old and under 40 years old, every five years.

In the group of participants older than 70 years old, approximately $0.5 \%$ developed gastric cancer within the next year. The proportion of the incidence of gastric cancer to the number of biopsies was 7 / 145 (4.8\%) compared to 35 / 964 (3.6\%) in all participants. Having adjusted for multiple variables using GEE model, the odds ratio for the incidences of gastric cancer within the next year turned to be 1.46 (95\%CI: 1.06-2.02). Cancer screening tends to be controversial in elderly people because of their remaining life expectancy. However, in Japan, the life expectancy is 80 years old for males and
86 years old for females [24], long enough for justifying cancer screening for people aged over 70 years.

For the 60-69 year-old age group, the incidence of gastric cancer exceeded $0.5 \%$ within the next three years. The proportion of the incidence of gastric cancer to the number of biopsies was 13 / 289 (4.5\%), and the proportion was higher than for gastric cancer in all participants. In the GEE model, the odds ratio for the incidence of gastric cancer within the next year was 1.59 (95\%CI: 1.23-2.06). Therefore, screening every two or three years may be appropriate.

For patients 50-59 years old, the incidence of gastric cancer was approximately $0.5 \%$ within the next four years. The proportion of the incidence of gastric cancer to the number of biopsies was 12 / 344 (3.5\%), similar to the proportion of gastric cancer in all participants. Based on the GEE model, the odds ratio for the incidence of gastric cancer within the next year was 1.94 (95\%CI: 1.31-2.86), and it was the highest among all the groups. Therefore, screening every four years may be reasonable.

For patients 40-49 years old, the incidence of gastric cancer was less than $0.5 \%$ within the next five years. The proportion of the incidence of gastric cancer to the number of biopsies was 3 / 159 (1.9\%), and the proportion was lower than that for all participants. Based on the GEE model, the odds ratio for the incidence of gastric cancer in the next year was 1.51 (95\%CI: 0.91-2.49), which attained no statistically significance. Therefore, screening every five or more years may be considered. However, in this group, all patients with gastric cancer had signet cell carcinoma, which has poor prognosis. This means that screening patients in this group may have to be considered carefully.

Among those under 40 years old, there were no patients with gastric cancer. Therefore, screening every five or more years may be appropriate for this age bracket.

In our study, 20 of 29 (69.0\%, 95\%CI: 49.2-84.7) patients with gastric cancer (excluding MALT lymphoma because of the differences in treatment) were detected in the early stage and treated with ESD. Compared to a previous study on barium $x$-ray screening program, the early stage detection rate in our study was high [25]. It is speculated that early detection of gastric cancer by nation which screening

Table 4 Positive biopsy ratio for gastric cancer over 5 years

\begin{tabular}{lccccrr}
\hline & $<\mathbf{4 0}$ & $\mathbf{4 0 - 4 9}$ & $\mathbf{5 0 - 5 9}$ & $\mathbf{6 0 - 6 9}$ & \multicolumn{2}{c}{ Total } \\
\hline $\mathbf{2 0 0 6}$ & $0 / 4$ & $0 / 27$ & $0 / 55$ & $2 / 57$ & $2 / 18$ & $4 / 161$ \\
$\mathbf{2 0 0 7}$ & $0 / 9$ & $1 / 32$ & $3 / 76$ & $2 / 62$ & $1 / 34$ & $7 / 213$ \\
$\mathbf{2 0 0 8}$ & $0 / 4$ & $1 / 35$ & $1 / 70$ & $2 / 53$ & $4 / 26$ & $9 / 188$ \\
$\mathbf{2 0 0 9}$ & $0 / 4$ & $1 / 18$ & $2 / 64$ & $3 / 50$ & $2 / 35$ & $0 / 32$ \\
$\mathbf{2 0 1 0}$ & $0 / 6$ & $0 / 47$ & $6 / 79$ & $13 / 289(4.5)$ & $7 / 145(4.8)$ & $35 / 964(3.6)$
\end{tabular}


Table 5 Odds ratios for the incidences of gastric cancer per year using a generalized estimating equation (GEE) in each age group, adjusted for age, gender, alcohol consumption, smoking, family history, past medical history of gastric ulcers, salt intake and body mass index (BMI)

\begin{tabular}{|c|c|c|c|c|}
\hline Age & Odds Ratio & 95\% Confidence Interval & Standard Deviation & p-value \\
\hline$<40$ & \multicolumn{4}{|c|}{ No incidence } \\
\hline $40-49$ & 1.51 & $0.91-2.49$ & 0.36 & 0.11 \\
\hline $50-59$ & 1.94 & $1.31-2.86$ & 0.38 & $<0.01$ \\
\hline $60-69$ & 1.59 & $1.23-2.06$ & 0.21 & $<0.01$ \\
\hline$\geq 70$ & 1.46 & $1.06-2.02$ & 0.24 & 0.02 \\
\hline
\end{tabular}

program in Japan has contributed to the reduced mortality from gastric cancer in the past decades [7]. In this regard, gastric cancer screening using EGD which detects gastric cancer in earlier stage than barium X-ray may be efficient.

In addition to that, early detection for gastric cancer was expected better prognosis than late detection. Previous study reported that the five years survival rate with gastric cancer in Stage I, II, III, IV were 99.1\%, 72.6\%, $45.9 \%$, and $7.2 \%$ respectively in Japan [26]. Among 24 patients with adenocarcinoma, at least 20 patients were in Stage IA or IB in our study. Within them, 16 patients were treated by ESD, which was less invasive than gastrectomy. Therefore, patients in our study were expected not only early detection for gastric cancer, but also better prognosis.

There are some limitations to this study. First, this study was a retrospective cohort study. We could not determine the magnitude of false negative results. There is a report, however, which reported that the false negative rate for gastric cancer screening by EGD was nil while 12 months follow-up [27]. Therefore, we would think the effect of false negatives negligible in our study. Second, our data did not include information on $\mathrm{H}$. pylori. It is said that $70-80 \%$ of people over 40 years old in Japan had $H$. pylori [28]. A previous randomized controlled study showed that $H$. pylori eradication reduced precancerous lesions without affecting overall incidence of gastric cancer [29]. For this reason, the information on $H$. pylori infection is unlikely to affect our results from 5 years cohort study. Third, population in our study may have selection bias, because of the study design. However, the incidence of gastric cancer in our study was similar to that in the previous study in Japan [30]. Therefore, this is also unlikely to affect the result. Finally, our data didn't have the information of atrophic gastritis. Previous study revealed that atrophic gastritis may be a major cause of gastric cancer [31]. For these reasons, additional studies are required to further evaluation.

\section{Conclusions}

A screening program for gastric cancer may be appropriate every year for healthy people over 70 years old, every two or three years for those 60-69 years old and every four years for those 50-59 years old. People younger than 50 years old may only need screenings every five years or more.

\section{Competing interests}

The authors declare that they have no competing pinterests.

\section{Authors' contributions}

DK conducted this study, decided study design, analyzed data, and drafted the manuscript. OT contributed to study design decision, performing data analysis and making manuscript. HA checked study design, reviewed manuscript and contribute to discussion. TF organized this study and contributed to discussion. All authors read and approved the final manuscript."

\section{Acknowledgements}

None.

Received: 31 March 2012 Accepted: 11 October 2012

Published: 17 October 2012

\section{References}

1. World Health Organization: The world health report. 1996. Accessed Sep.16, 2011, at http://www.who.int/whr/1997/media_centre/50facts/en.

2. Health, Labour and Welfare Ministry, Cancer research team: Effectiveness evaluation based gastric cancer screening guideline; 2006. Accessed Sep.16, 2011, at http://dcanscreen.ncc.go.jp/pdf/guideline/gastric_guide060714.pdf.

3. Mizoue T, Yoshimura T, Tokui N, et al: Prospective study of screening for stomach cancer in Japan. Int J Cancer 2003, 106:103-107.

4. Llorens P: Gastric cancer mass survey in Chile. Semin Surg Oncol 1991, 7:339-343.

5. Pisani P, Oliver WE, Parkin DM, Alvarez N, Vivas J: Case-control study of gastric cancer screening in Venezuela. Br J Cancer 1994, 69:1102-1105.

6. Leung WK, Wu MS, Kakugawa Y, et al: Screening for gastric cancer in Asia: current evidence and practice. Lancet Oncol 2008, 9:279-287.

7. Hisamichi S, Sugawara N, Fukao A: Effectiveness of gastric mass screening in Japan. Cancer Detect Prev 1988, 11:323-329.

8. Fukao A, Tsubono Y, Tsuji I, HI S, Sugahara N, Takano A: The evaluation of screening for gastric cancer in Miyagi Prefecture, Japan: a populationbased case-control study. Int J Cancer 1995, 60:45-48.

9. Gastric carcinoma. In DynaMed [database online]. EBSCO Publishing. http:// web.ebscohost.com/dynamed/detail?sid=eec61 ce4-ee17-4e2c-952b2ea463997ac9\%40sessionmgr10\&vid=2\&hid=18\&bdata=JnNpdGU9ZHluYW1 IZC1saXZIJnNjb3BIPXNpdGU\%3d\#db=dme\&AN=116155. Updated November 19, 2011.Accessed November 28, 2011.

10. Hamashima C, Shibuya D, Yamazaki H, et al: The Japanese guidelines for gastric cancer screening. Jpn J Clin Oncol 2008, 38:259-267.

11. Japan Public Health Association: Report of the Research Group for Evaluation of Effectiveness of Cancer Screening in Japan; 1998.

12. Kaneko EHH, Kasugai T: 4th report of endoscopic complications: results of the Japan Gastroenterological Endoscopy Society survey. Japanese: Gastroenterol Endosc; 2004:46.

13. Dan YY, So JB, Yeoh KG: Endoscopic screening for gastric cancer. Clin Gastroenterol Hepatol 2006, 4:709-716.

14. Kobayashi D, Takahashi O, Fukui T: Glasziou PP. Ann Oncol: Optimal prostate-specific antigen screening interval for prostate cancer; 2011. 
15. Hanley JA, Negassa A, Edwardes MD, Forrester JE: Statistical analysis of correlated data using generalized estimating equations: an orientation. Am J Epidemiol 2003, 157:364-375.

16. Barstad B, Sorensen TI, Tjonneland A, et al: Intake of wine, beer and spirits and risk of gastric cancer. Eur J Cancer Prev 2005, 14:239-243.

17. Doll R, Peto R, Boreham J, Sutherland I: Mortality from cancer in relation to smoking: 50 years observations on British doctors. Br J Cancer 2005, 92:426-429.

18. Tsugane S, Sasazuki S: Diet and the risk of gastric cancer: review of epidemiological evidence. Gastric Cancer 2007, 10:75-83.

19. Yang P, Zhou Y, Chen B, et al: Overweight, obesity and gastric cancer risk: results from a meta-analysis of cohort studies. Eur J Cancer 2009, 45:2867-2873.

20. Lipsitz SR, Kim K, Zhao L: Analysis of repeated categorical data using generalized estimating equations. Stat Med 1994, 13:1149-1163.

21. Hardin J, Hilbe J: Generalized Estimating Equations. London: Chapman and Hall/CRC; 2003.

22. Ballinger $\mathrm{G}$ : Using generalized estimating equations for longitudinal data analysis. Organizational Research Methods 2004, 7:127-150.

23. Clopper C: The use of confidence or fiducial limits illustrated in the case of the binomial. Biometrika 1934, 26:404-413.

24. World Health Organization. Japan. Accessed Sep.16, 2011, at http://www. who.int/countries/jpn/en/.

25. Kunisaki C, Ishino J, Nakajima S, et al: Outcomes of mass screening for gastric carcinoma. Ann Surg Oncol 2006, 13:221-228.

26. Japanese Association of Clinical Cancer Centers. Accessed Sep 12, 2012, at http://www.gunma-cc.jp/sarukihan/seizonritu/seizonritu.html.

27. Vradelis S, Maynard N, Warren BF, Keshav S, Travis SP: Quality control in upper gastrointestinal endoscopy: detection rates of gastric cancer in Oxford 2005-2008. Postgrad Med J 2011, 87:335-339.

28. Asaka M, Kimura T, Kudo M, et al: Relationship of Helicobacter pylori to serum pepsinogens in an asymptomatic Japanese population. Gastroenterology 1992, 102:760-766.

29. Wong BC, Lam SK, Wong WM, et al: Helicobacter pylori eradication to prevent gastric cancer in a high-risk region of China: a randomized controlled trial. JAMA 2004, 291:187-194.

30. Inoue M, Tsugane S: Epidemiology of gastric cancer in Japan. Postgrad Med J 2005, 81:419-424.

31. Derakhshan $\mathbf{M H}$, Malekzadeh $\mathrm{R}$, Watabe $\mathrm{H}$, et al: Combination of gastric atrophy, reflux symptoms and histological subtype indicates two distinct aetiologies of gastric cardia cancer. Gut 2008, 57:298-305.

doi:10.1186/1471-230X-12-144

Cite this article as: Kobayashi et al:: The optimal screening interval for gastric cancer using esophago-gastro-duodenoscopy in Japan. BMC Gastroenterology 2012 12:144.

\section{Submit your next manuscript to BioMed Central and take full advantage of:}

- Convenient online submission

- Thorough peer review

- No space constraints or color figure charges

- Immediate publication on acceptance

- Inclusion in PubMed, CAS, Scopus and Google Scholar

- Research which is freely available for redistribution 